\title{
Mediastinal Germ Cell Tumor with Somatic-Type Malignancy
}

National Cancer Institute

\section{Source}

National Cancer Institute. Mediastinal Germ Cell Tumor with Somatic-Type Malignancy.

NCl Thesaurus. Code C45732.

A rare extrag onadal germ cell tumor that arises from the mediastinum and is associated with the presence of a somatic-type malignant component. The somatic malignancy is usually a sarcoma (e.g., embryonal rhabdomyosarcoma, angiosarcoma, or leiomyosarcoma), adenocarcinoma, squamous cell carcinoma, adenosquamous carcinoma, or primitive neuroectodermal tumor. The prognosis is poor. 